\title{
The Neuropeptide Oxytocin Facilitates Pro-Social Behavior and Prevents Social Avoidance in Rats and Mice
}

\author{
Michael Lukas', Iulia Toth', Stefan O Reber', David A Slattery', Alexa H Veenema ${ }^{1,2}$ and Inga D Neumann*,' \\ 'Department of Behavioral and Molecular Neurobiology, University of Regensburg, Regensburg, Germany
}

\begin{abstract}
Social avoidance and social phobia are core symptoms of various psychopathologies but their underlying etiology remains poorly understood. Therefore, this study aims to reveal pro-social effects of the neuropeptide oxytocin (OT), under both basal and stressinduced social avoidance conditions in rodents using a social preference paradigm. We initially show that intracerebroventricular (i.c.v.) application of an OT receptor antagonist (OTR-A) in naïve male rats $(0.75 \mu \mathrm{g} / 5 \mu \mathrm{l})$, or mice $(20 \mu \mathrm{g} / 2 \mu \mathrm{l})$, reduced social exploration of a novel con-specific indicative of attenuated social preference. Previous exposure of male rats to a single social defeat resulted in loss of their social preference and social avoidance, which could be restored by i.c.v. infusion of synthetic OT $(0.1 \mu \mathrm{g} / 5 \mu \mathrm{l}) 20 \mathrm{~min}$ before the social preference test. Although the amygdala has been implicated in both social and OT-mediated actions, bilateral OTR-A (0.I $\mu$ g/I $\mu$ I) or $\mathrm{OT}(0.01 \mu \mathrm{g} / \mid \mu \mathrm{l})$ administration into various subnuclei of the amygdala did not affect basal or stress-induced social preference behavior, respectively. Finally, we demonstrate the social specificity of these OT-mediated effects by showing that neither an arginine vasopressin VIa receptor antagonist $(0.75 \mu \mathrm{g} / 5 \mu \mathrm{l}$, i.c.V.) nor the anxiogenic drug pentylenetetrazol (I5 mg/kg, i.p.) altered social preference, with OTR-A not affecting non-social anxiety on the elevated plus-maze. Overall, the data indicate that the basal activity of the endogenous brain OT system is sufficient to promote natural occurring social preference in rodents while synthetic OT shows potential to reverse stress-induced social avoidance and might thus be of use for treating social phobia and social dysfunction in humans. Neuropsychopharmacology (201 I) 36, 2159-2168; doi:10.1038/npp.201 I.95; published online I 5 June 201 I
\end{abstract}

Keywords: social preference; social interaction; social defeat; amygdala; vasopressin; anxiety

\section{INTRODUCTION}

Animal and human studies indicate a facilitatory role of the neuropeptide oxytocin (OT) in a broad variety of social interactions. Released within the brain (for reviews, see Landgraf and Neumann, 2004; Neumann, 2009), OT promotes various aspects of social behavior in both females and males related to reproduction, including the onset and fine-tuned maintenance of maternal behavior in lactation (Bosch et al, 2005; Kendrick, 2000; McCarthy, 1990; Pedersen et al, 1982; van Leengoed et al, 1987), receptive behavior of female rats (Schulze and Gorzalka, 1991; Witt and Insel, 1991), various aspects of sexual behavior in males (Argiolas and Melis, 2004), as well as pair bonding in female voles (Cho et al, 1999; Williams et al, 1994). Furthermore, chronic central OT administration increases social interactions of male with female rats (Witt et al, 1992). Also, OT has a role in social recognition in both male (Popik and van Ree, 1991) and female (Engelmann et al, 1998) rats, which has been confirmed in OT and OT receptor knockout mice,

*Correspondence: Dr ID Neumann, Universitaetsstrasse 31, 93053 Regensburg, Germany, Tel: + 49941943 3053, Fax: + 49941943 3052, E-mail: inga.neumann@biologie.uni-regensburg.de

${ }^{2}$ Current address: Department of Psychology, Boston College, 140 Commonwealth Avenue, McGuinn 522, Chestnut Hill, MA 02467, USA.

Received 4 March 20 II; revised I2 April 20 I ; accepted I0 May 20II which display impaired social memory (Ferguson et al, 2000; Choleris et al, 2003; Takayanagi et al, 2005).

Intranasal OT administration has been shown to affect many aspects of human sociability ranging from social perception, increased gazing toward the eye region (Gamer et al, 2010; Guastella et al, 2008), and improved recognition of emotional facial expressions (Domes et al, 2007; Savaskan et al, 2008) to complex social behaviors like trust, social-risk taking, and empathy (Baumgartner et al, 2008; Hurlemann et al, 2010; Kosfeld et al, 2005). The amygdala, a brain region strongly involved in social perception and emotional processing, has been implicated as one of the key regions mediating neuronal actions of OT on social behaviors in humans (Baumgartner et al, 2008; Gamer et al, 2010; Hurlemann et al, 2010; Kirsch et al, 2005) as well as in rodents (Choleris et al, 2007; Ferguson et al, 2001; Lee et al, 2007).

In addition to these multiple effects on sociability, brain OT functions as an endogenous anxiolytic neuropeptide in females (Neumann et al, 2000b) and males (Waldherr and Neumann, 2007), and acute or chronic administration of synthetic OT reduces anxiety-related behavior in rodents (Blume et al, 2008; Ring et al, 2006; Slattery and Neumann, 2010; Windle et al, 1997). The anxiolytic effect of OT could be localized within both the amygdala of females (Bale et al, 2001; Neumann, 2002) and the hypothalamic paraventricular nucleus (PVN) of males (Blume et al, 2008). On the 
basis of these behavioral effects, we recently succeeded in showing that the prolonged anxiolysis observed following sexual activity in male rats is mediated by a matinginduced release of OT within the PVN (Waldherr and Neumann, 2007).

The dual pro-social and anxiolytic effects of OT, that the endogenous OT system may also reduce social anxiety and increase social preference in a non-reproductive context. In support of this notion, OT homologues, such as isotocin and mesotocin, have been shown to promote sociability in fish and birds, respectively (Goodson et al, 2009; Thompson and Walton, 2004). A transfer of this concept to rodents is strongly supported by data demonstrating that the prominent pro-social effect of 3,4 methylenedioxymethamphetamine ('ecstasy') in rats is, at least partially, mediated via the endogenous OT system (Thompson et al, 2007). Such facilitatory effects of OT on social preference are of particular importance in the context of social dysfunctions in humans, which represent core symptoms of various neuropsychiatric disorders including anxiety- and depression-related diseases (Merikangas and Angst, 1995) and autism spectrum disorders (Caronna et al, 2008). Interestingly, intranasal or intravenous OT has recently been shown to promote social approach and social comprehension in autistic patients (Andari et al, 2010; Guastella et al, 2009, 2010; Hollander et al, 2007).

Here, we hypothesize that brain OT promotes naturally occurring social preference in rats and mice, and prevents social defeat-induced social avoidance. Specifically, we predict that blockade of the endogenous OT system by administration of a specific OT receptor antagonist (OTRA), both intracerebroventricular (i.c.v.) and into various sub-regions of the amygdala, can reduce the preference for a social stimulus over a non-social stimulus. Further, we predict that central administration of synthetic OT will reverse social defeat-induced social avoidance. Finally, in order to exclude any direct interaction between non-social and social anxiety, effects of the anxiogenic compound pentylenetetrazol (PTZ) on social preference and of the OTR-A on non-social anxiety were tested.

\section{SUBJECTS AND METHODS}

\section{Animals}

Adult male Wistar rats (250-300 g) and adult male C57BL/6 mice (20-24 g) were purchased from Charles River (Sulzfeld, Germany) and group housed in standard cages (rats: $55 \times 22 \times 18 \mathrm{~cm}$, mice: $16 \times 22 \times 14 \mathrm{~cm}$ ) for habituation to the laboratory facilities under standard laboratory conditions (12:12 h light: dark cycle, lights on at 0600 hours, $22{ }^{\circ} \mathrm{C}, 60 \%$ humidity, food, and water ad libitum). After surgery, subjects were transferred to observation cages (rats: $40 \times 24 \times 36 \mathrm{~cm}$, mice: $16 \times 22 \times 14 \mathrm{~cm}$ ) and single housed till the end of the experiment. For social defeat, male rats selectively bred for low anxiety-related behavior (LAB) which show a reliable high level of inter-male aggression (Beiderbeck et al, 2007; Neumann et al, 2010), were used as residents. Experiments were performed in the first $3 \mathrm{~h}$ of the light or dark phase and conducted in accordance with the Guide for the Care and Use of Laboratory Animals of the Government of Oberpfalz and the guidelines of the NIH.

\section{Social Preference Paradigm}

The social preference paradigm in rats was based on the social approach-avoidance test previously described in mice (Berton et al, 2006). In our study, the test has been modified and used both in rats and mice. The species-dependent durations of habituation, presence of object stimulus, presence of social stimulus, and light conditions were determined based on a series of pilot experiments assessing the duration-dependent exploratory behavior in rats (arena and home cage) and mice (arena).

Social preference in novel arena. Rats and mice were placed in a novel arena (rat: $40 \times 80 \times 40 \mathrm{~cm}$, red light; mouse: $28 \times 46 \times 27 \mathrm{~cm}, 100 \mathrm{lux}$; Figure 1). After $30 \mathrm{~s}$ of habituation, an empty wire-mesh cage (object stimulus; rat: $20 \times 9 \times 9 \mathrm{~cm}$; mouse: $11 \times 9 \times 6 \mathrm{~cm})$ was placed at one side wall of the arena for $4 \mathrm{~min}$ (rats) or $2.5 \mathrm{~min}$ (mice). The empty cage was then exchanged by an identical cage containing an unknown male con-specific (social stimulus) for additional $4 \mathrm{~min}$ (rats) or $2.5 \mathrm{~min}$ (mice). Before each trial, the arena was cleaned with water containing a low concentration of detergent. In rats, all tests took place during the active phase starting $1 \mathrm{~h}$ after lights off using an unknown Wistar rat as social stimulus. Mice were tested in the early light phase ( $1 \mathrm{~h}$ after lights on) using an unknown male CD1 mouse as social stimulus.

Social preference in home cage. In order to demonstrate that OT-induced changes in social preference are to a large extent independent of the environment, light conditions, and the quality of the social stimulus, rats were additionally tested for social preference in their home cage with slight modifications. Specifically, a red plastic ring (inner diameter $8.3 \mathrm{~cm}$, outer diameter $9.4 \mathrm{~cm}, 2.8 \mathrm{~cm}$ wide) was used as object stimulus during the 4-min object stimulus period. Subsequently, the time investigating a freely moving 3-week-old male Wistar rat-used as social stimulus - was assessed for additional $4 \mathrm{~min}$ after removal of the ring. A juvenile rat was chosen as social stimulus because it does not elicit aggressive behavior in the experimental rats. The social preference test was performed in the light phase under standard laboratory illumination.

Each test procedure was videotaped and scored afterward by an observer blind to the treatment using JWatcher behavioral observation software (V 1.0, Macquarie University and UCLA). Object and social stimulus investigation times were scored by measuring the time the rat/mouse spent in active olfactory investigation. As total exposure time differs between rats and mice, data are presented as the percentage of time investigating the object stimulus and the percentage of time investigating the social stimulus, respectively, that is, investigation time/total time $(4 / 2.5 \mathrm{~min}) \times 100 \%$. A significantly higher percentage of investigation of the social $v s$ the non-social stimulus was considered social preference. Loss of this difference was defined as lack of social preference or accordingly social avoidance. 


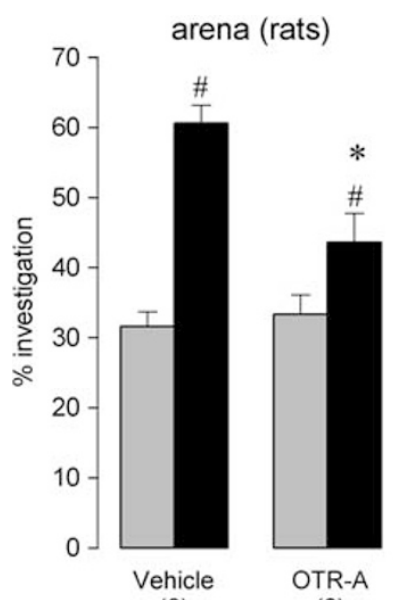

(6)

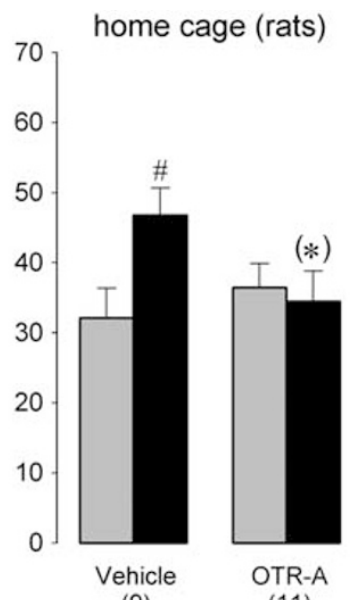

(9)

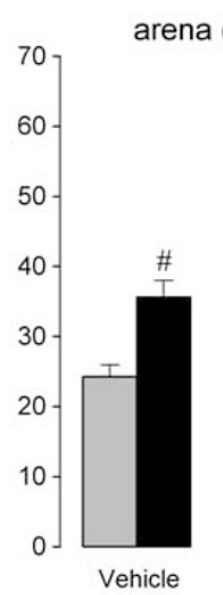

(10)

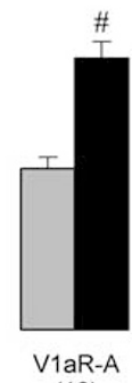

(10)
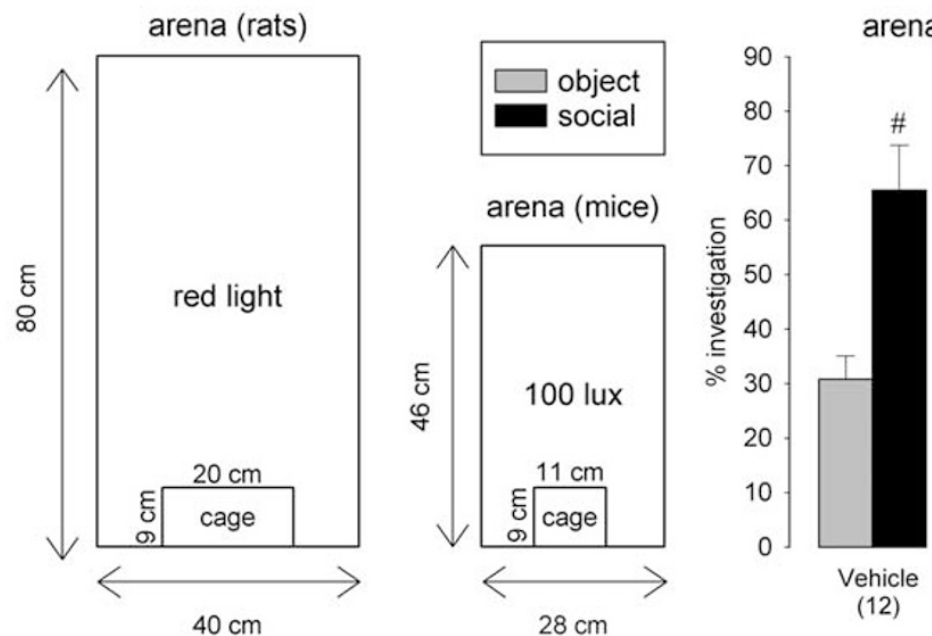

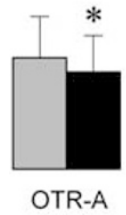

(7)

Figure I Effects of i.c.v. administration of an oxytocin receptor antagonist (OTR-A; rats: $0.75 \mu \mathrm{g} / 5 \mu \mathrm{l}$; mice $20 \mu \mathrm{g} / 2 \mu \mathrm{l}$ ) or vasopressin receptor antagonist

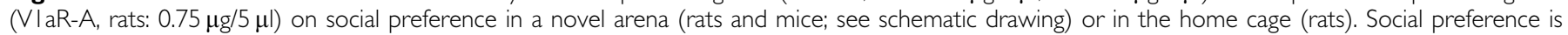

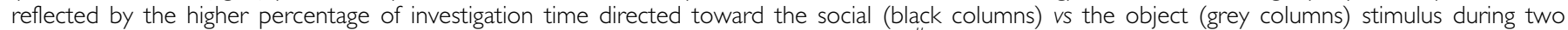

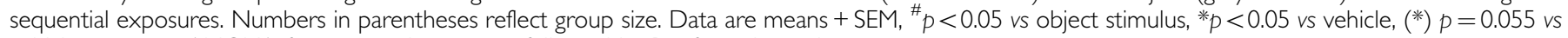
vehicle; two-way ANOVA for repeated measures followed by Bonferroni post hoc test.

\section{Elevated Plus-Maze}

The elevated plus-maze was used to assess the effects of the OTR-A or of PTZ on non-social anxiety-related behavior in both rats and mice (Pellow et al, 1985). It consisted of two opposing open arms (rat: $50 \times 10 \mathrm{~cm}$; mice: $6 \times 30 \mathrm{~cm} ; 100 \mathrm{lux}$ ) and two opposing closed arms (rat: $50 \times 10 \times 40 \mathrm{~cm}$; mice: $6 \times 30 \times 17 \mathrm{~cm} ; 20 \mathrm{lux})$ connected by a neutral area. The apparatus was made of dark grey plastic, elevated to a height of $80 \mathrm{~cm}$ (rats) or $35 \mathrm{~cm}$ (mice) above the floor, and surrounded by an opaque curtain to avoid external disturbance. Before each trial, the maze was cleaned with water containing a low concentration of detergent. Rats and mice were placed individually in the central area facing a closed arm and were allowed to explore the maze for $5 \mathrm{~min}$. The percentage of time spent on the open arms was assessed as anxiety-related behavior (time on open arms/time on open and closed arms $\times 100$ ); the number of entries in the closed arms as measurement for locomotion was recorded by means of a video camera mounted above the platform and scored by a trained observer (Plus-maze version 2.0; E. Fricke). The elevated plus-maze testing was performed in the light phase.

\section{Black-White Box}

To assess non-social anxiety-related behavior in an additional test, rats were monitored in the black-white box for 5 min (Waldherr and Neumann, 2007; Slattery and Neumann, 2010; white compartment: $40 \times 50 \mathrm{~cm}, 350$ lux; black compartment: $40 \times 30 \mathrm{~cm}, 70$ lux). The black-white box was surrounded by an opaque curtain to avoid external disturbances. Rats were placed in the dark compartment, and the percentage time spent in the white compartment (time in white compartment/total time $(5 \mathrm{~min}) \times 100 \%)$ was assessed as anxiety-related behavior. Testing was performed during the early-dark phase.

\section{Experimental Design}

Involvement of endogenous OT in social preference in rats and mice. To reveal the involvement of the brain OT system in basal social preference, the following experiments were carried out in male rats and mice (for group sizes see corresponding figures).

Rats. Rats were i.c.v. infused with either OTR-A $(0.75 \mu \mathrm{g} / 5 \mu \mathrm{l})$ or vehicle $20 \mathrm{~min}$ (see Supplementary 
Materials and Methods) before testing in the social preference paradigm in the novel arena. A separate group of rats received the same treatments and were tested for social preference in their home cage. In addition, another group of rats was i.c.v. infused with the selective vasopressin 1a receptor antagonist (V1aR-A; $0.75 \mu \mathrm{g} / 5 \mu \mathrm{l})$ or vehicle $20 \mathrm{~min}$ (see Supplementary Materials and Methods) before social preference in the novel arena to test if the closely related brain neuropeptide vasopressin also influences social preference. Finally, to localize the positive effect of endogenous OT on social preference, additional rats were bilaterally infused with OTR-A at two different doses $(0.1$ and $1.0 \mu \mathrm{g} / 1 \mu \mathrm{l})$ or vehicle into the central, medial, or basolateral amygdaloid nuclei (see Supplementary Materials and Methods) and tested in the social preference paradigm in the arena 10 min later.

Mice. Mice were i.c.v. infused with either OTR-A $(20 \mu \mathrm{g} / 2 \mu \mathrm{l}$ or $2 \mu \mathrm{g} / 2 \mu \mathrm{l})$ or vehicle (see Supplementary Materials and Methods) $20 \mathrm{~min}$ before testing in the social preference paradigm in the novel arena.

Social defeat-induced social avoidance and reversal by synthetic $O T$ in rats. First, we aimed to verify whether exposure to a single social defeat (see Supplementary Materials and Methods) induces social avoidance. Rats were tested in the social preference paradigm $2 \mathrm{~h}$ after onset of the 30-min social defeat using either the former defeater rat or an unknown male rat as social stimulus. Second, in order to test the hypothesis that social defeat-induced social avoidance can be reversed by OT, male rats were socially defeated and OT $(0.1 \mu \mathrm{g} / 5 \mu \mathrm{l})$ or vehicle was infused (i.c.v., see Supplementary Materials and Methods) $20 \mathrm{~min}$ before the social preference test using the former defeater rat as social stimulus. Third, to localize the positive effect of OT on social preference in defeated rats, socially-defeated rats were bilaterally infused with either OT $(0.01 \mu \mathrm{g} / 1 \mu \mathrm{l})$ or vehicle into the central or medial nucleus of the amygdala (see Supplementary Materials and Methods) 10 min before being tested in the social preference paradigm (for group sizes see figures).

Link between non-social anxiety and social preference in rats and mice. To test if the lack of social preference after blockade of brain OT receptors is specific for social anxiety, additional groups of rats and mice received the following treatments (for group sizes see figures).

Rats. Rats were i.c.v. treated with OTR-A $(0.75 \mu \mathrm{g} / 5 \mu \mathrm{l})$ or vehicle (see Supplementary Materials and Methods) $20 \mathrm{~min}$ before testing for non-social anxiety-related behavior in the black-white box.

Mice. Mice were i.c.v. treated with OTR-A $(20 \mu \mathrm{g} / 2 \mu \mathrm{l})$ or vehicle (see Supplementary Materials and Methods) 20 min before testing non-social anxiety-related behavior on the elevated plus-maze.

Rats. To further test for a possible interaction between general state anxiety and social preference, rats were given a single injection of the anxiogenic agent PTZ (15 mg/kg, i.p.) or vehicle (see Supplementary Materials and Methods) and tested 15 min later on the elevated plus-maze or in the social preference paradigm.

\section{Statistics}

For statistical analysis PASW/SPSS Statistics (Version 17.0) was used. Social preference was statistically analyzed using ANOVA for repeated measures (two-way: factors treatment $\times$ stimulus; three-way: factors treatment $\times$ stimulus $\times$ defeat) followed by a Bonferroni post hoc test when appropriate. All relevant F-values are provided in Table 1. Non-social anxiety behavior was analyzed using the Student's $t$-test. Significance was accepted at $p<0.05$.

\section{RESULTS}

\section{Involvement of Endogenous OT in Social Preference}

Rats. I.c.v. OTR-A-treated rats showed a significant decrease in social investigation during the social preference test in the arena $(p<0.01 v s$ vehicle; Figure 1$)$. Still, both OTR-A- and vehicle-treated rats investigated the social stimulus significantly longer than the object stimulus $(p<0.05$; Figure 1$)$, thereby demonstrating social preference. Central infusion of the V1aR-A did not change social investigation time, and thus, both vehicle- and V1aR-Atreated groups demonstrated a preference for the social compared with the object stimulus $(p<0.01$, Figure 1$)$.

In line with the results in the novel arena, when tested in their home cage, i.c.v. OTR-A-treated rats showed a decrease in social investigation $(p=0.055$ vs vehicle; Figure 1). As a result, OTR-A-treated rats showed no social preference (stimulus $v s$ object: $p=0.673$, Figure 1 ).

Bilateral infusion of either 0.1 or $1.0 \mu \mathrm{g} / \mu \mathrm{l}$ OTR-A into either the central, medial, or basolateral amygdala did not result in altered social investigation times compared with respective vehicle-groups (Figure 2). All rat groups independent of treatment showed social preference $(p<0.05$ vs object stimulus, Figure 2).

Mice. Similar to rats, i.c.v. OTR-A-treated mice showed a significant decrease in social investigation $(p<0.05$ vs vehicle, Figure 1). Moreover, OTR-A-treatment $(20 \mu \mathrm{g} / 2 \mu \mathrm{l})$ induced social avoidance in mice, thereby completely preventing social preference in the novel arena $(p=0.70$ vs object stimulus, Figure 1). A 10-fold lower dose did not alter any behavior assessed in the social preference paradigm (data not shown).

\section{Social Defeat-Induced Social Avoidance and Reversal by I.C.V. OT Infusion in Rats}

To demonstrate that a single exposure to social defeat induces social avoidance, male rats were defeated by an aggressive larger male rat and then tested in the social preference paradigm $2 \mathrm{~h}$ later. When an unknown male rat was used as social stimulus, both control and defeated rats showed a preference for the unknown social stimulus $(p<0.05$ vs object stimulus, Figure 3a). In contrast, exposure of the defeated males to their former defeater rat resulted in social avoidance, as demonstrated by a significant decrease in social stimulus investigation $(p<0.05 v s$ control rats, Figure $3 \mathrm{~b})$ and a lack of social preference $(p=0.119 v s$ object stimulus, Figure $3 b)$.

To test whether OT can reverse defeat-induced social avoidance, defeated rats were i.c.v. or locally infused with 
Table I Relevant Overall Effects for All Social Preference Data (Two-Way or Three-Way ANOVA for Repeated Measures)

Factor stimulus

Factor stimulus $\times$ treatment

Overall effects for Figure 1

Arena (rats)

I.c.v. OTR-A

$\mathrm{F}_{(1,10)}=58.5 ; p<0.00 \mathrm{I}$

$F_{(1,10)}=11.9 ; p=0.006$

I.c.v. VIaR-A

$F_{(I, 18)}=41.8 ; p<0.001$

$F_{(1,18)}=1.09 ; p=0.309$

Home cage (rat)

I.c.v. OTR-A

$F_{(1,18)}=3.42 ; p=0.081$

$F_{(I, 18)}=5.88 ; p=0.026$

Arena (mice)

I.c.v. OTR-A

$F_{(I, 17)}=|5.3 ; p<0.00|$

$F_{(I, 17)}=20.7 ; p<0.001$

Overall effects for Figure 2

Central amygdala $(0 .|\mu g /| \mu \mid)$

$F_{(1,12)}=61.5 ; p<0.001$

Central amygdala $(|.0 \mu \mathrm{g} /| \mu \mid)$

$F_{(1,12)}=42.3 ; p<0.001$

Medial amygdala

$F_{(1,14)}=37.3 ; p<0.001$

Basolateral amygdala

$F_{(I, 18)}=\mid 8.3 ; p<0.001$

Factor stimulus $\times$ treatment
$F_{(I, 12)}=0.54 ; p=0.476$
$F_{(I, 12)}<0.001 ; p=0.987$
$F_{(I, 14)}=0.64 ; p=0.439$
$F_{(1,18)}=0.44 ; p=0.515$

Overall effects for Figure 3

Unknown male (a)

$F_{(1,12)}=10.5 ; p=0.007$

Factor stimulus $\times$ defeat

Defeater male (b)

$F_{(I, 8)}=0.52 ; p=0.490$

$F_{(1,12)}=0.004 ; p=0.950$

$F_{(1,8)}=10.9 ; p=0.013$

Overall effects for Figure 4

I.c.v. OT (a)

$F_{(I, 46)}=24.5 ; p<0.001$

Factor stimulus $\times$ treatment $\times$ defeat

Local OT (b)

$F_{(1,29)}=6.37 ; p=0.017$

$F_{(1,46)}=0.32 ; p=0.324$

Factor stimulus $\times$ treatment

$F_{(1,29)}=1.96 ; p=0.159$

Overall effects for Figure 5

PTZ (c)

$F_{(1,11)}=23.7 ; p<0.001$

Factor stimulus $\times$ treatment

$F_{(I, 1)}=0.08 ; p=0.785$

either synthetic OT or vehicle 20 min prior to the social preference test. Whereas undefeated rats treated with either vehicle or OT showed social preference $(p<0.05$, Figure 4$)$, vehicle-treated defeated rats lost their preference for the social stimulus (former defeater, $p=0.468$ vs object stimulus, Figure $4 \mathrm{a}$ ). The stress-induced social avoidance seen in defeated rats could be prevented by i.c.v. OT $20 \mathrm{~min}$ resulting in reinstatement of social preference toward the former defeater $(p<0.05$ social $v s$ object stimulus, Figure 4a). Infusion of synthetic OT into either the central or medial amygdala of defeated rats failed to increase social investigation time toward the former defeater, resulting in a similar lack of social preference as seen in vehicle-treated defeated rats (Figure $4 \mathrm{~b}$ ).

\section{Involvement of General Anxiety in the Display of Social Preference in Rats and Mice}

Rats. I.c.v. OTR-A infusion in male rats did not change non-social anxiety-related behavior in the black-white box (percentage time spent in the white compartment; $t_{(14)}=1.07, p=0.302$, Figure 5a).

Mice. Similarly, non-social anxiety-related behavior on the elevated plus-maze following i.c.v. OTR-A infusion remained unchanged in mice $\left(t_{(9)}=-0.65, p=0.531\right.$, Figure 5a).

Rats. As expected, injection of the anxiogenic drug PTZ in rats increased anxiety-related behavior on the elevated plusmaze as demonstrated by a reduction in the percentage of time spent on the open arms of PTZ-treated rats compared with vehicle-treated rats $\left(t_{(16)}=-3.36, p<0.01 v s\right.$ vehicle, Figure 5b). Importantly, PTZ did not impair social preference. Here, both vehicle- and PTZ-treated rats spent more time investigating the social stimulus than the object stimulus $(p<0.05$, Figure $5 c)$.

\section{DISCUSSION}

The present results provide the first direct evidence that the endogenous OT system facilitates social preference in both male rats and mice. More specifically, central blockade of OT receptors, using an OTR-A, significantly reduced naturally occurring social preference toward a novel con-specific in both species. Moreover, centrally applied synthetic OT was found to rescue normal social preference that had been abolished by previous exposure to an acute social defeat. Furthermore, we were able to dissociate social 


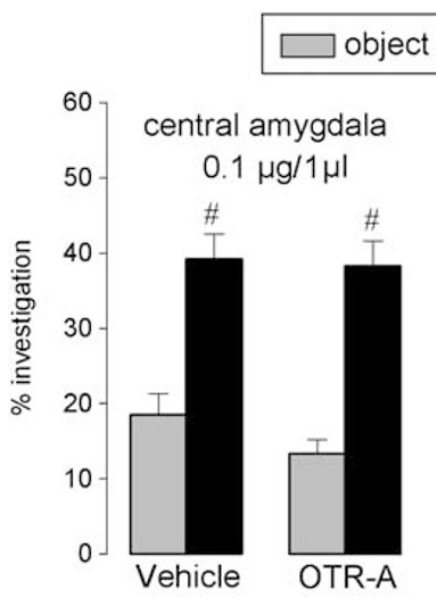

(6)

(8)

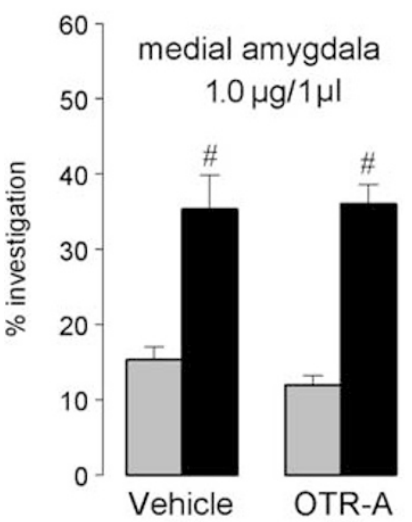

(8)

(8)

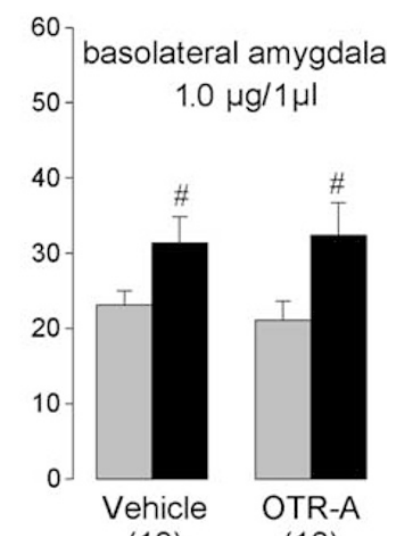

(10)

(10)

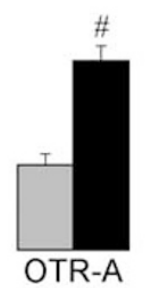

(8)
(6)

Figure 2 Effects of infusion of an oxytocin receptor antagonist (OTR-A, $0.1 \mu \mathrm{g} / \mid \mu \mathrm{l}$ and $|.0 \mu \mathrm{g} /| \mu \mathrm{l}$ ) bilaterally into the central, medial, or basolateral amygdala on social preference behavior of male rats. Social preference is reflected by the higher percentage of investigation time directed toward the social (black columns) vs the object (grey columns) stimulus during two sequential exposures. Numbers in parentheses reflect group size. Data are means + SEM, ${ }^{\#} p<0.05$ vs object stimulus, two-way ANOVA for repeated measures followed by Bonferroni post hoc test.

avoidance from non-social anxiety, as the anxiogenic drug PTZ did not alter social preference in rats, while centrally infused OTR-A did not alter non-social anxiety in either rats and mice. Taken together, these findings highlight a role of the OT system in social preference under both basal conditions and during stress-induced social avoidance or social phobia.

Most animal research investigating the pro-social properties of neuropeptides belonging to the OT-vasopressin family has been performed either in relation to reproduction or in non-mammalian species (see Introduction). We are now able to demonstrate pro-social effects of the endogenous OT system in social preference in rats and mice as well as of synthetic OT in a rodent model of defeatinduced loss of social preference and social avoidance. Specifically, central application of an OTR-A and, thus, blockade of intracerebral OT receptors attenuated social preference in rats, and dose-dependently caused social avoidance in mice. Together, these results indicate the involvement of the brain OT system in normal social

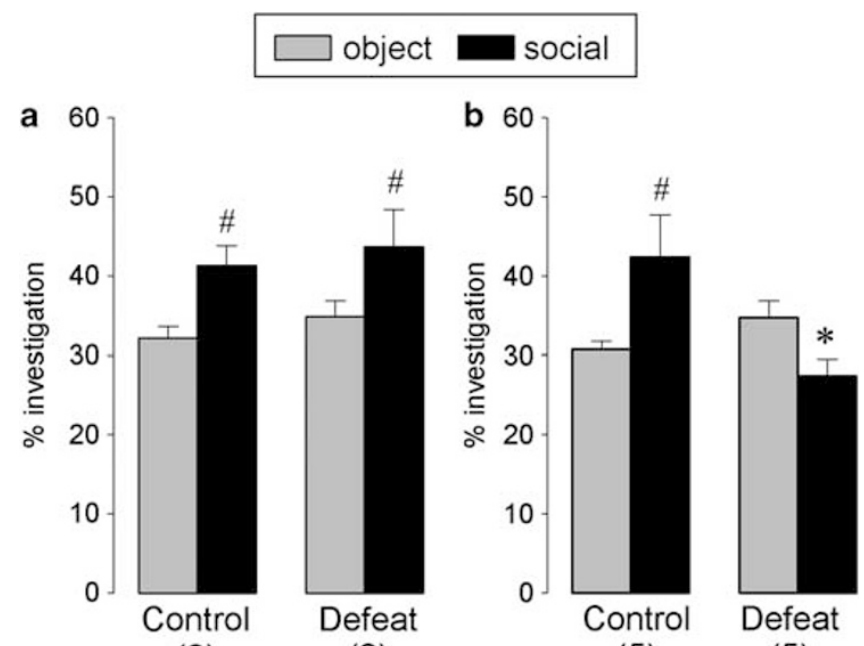

(6)
(5)

Figure 3 Social preference behavior of socially defeated and control rats. (a) Control and defeated rats were exposed to an unknown male as social stimulus during the social preference test. (b) Socially defeated rats were exposed to their individual defeater rat as social stimulus during the social preference test. Social preference is reflected by a higher percentage of investigation time directed toward the social (black columns) vs the object (grey columns) stimulus during two sequential exposures. Numbers in parentheses reflect group size. Data are means + SEM, ${ }^{*} p<0.05$ vs nondefeated control, \#p<0.05 vs object stimulus; two-way ANOVA for repeated measures followed by Bonferroni post hoc test.

preference in two different species. Importantly, these results provide the first direct evidence that OT can have a pro-social effect on male-male interactions and not only on reproduction-related behaviors such as pair-bonding, maternal or sexual behaviors. Consequently, basal and/or social stimulus-induced release of OT within the brain (Landgraf and Neumann, 2004; Neumann, 2009) and subsequent OT-receptor interactions within discrete brain regions may underlie the motivation for social approach. Our finding of a facilitatory effect of endogenous OT on rodent social interaction is in line with a study showing that the high levels of sociability observed after 3,4 methylenedioxymethamphetamine ('ecstasy') consumption are prevented by central infusion of an OTR-A in male rats (Thompson et al, 2007). We further demonstrate that the promotion of social preference by the OT system is a robust effect as it could be observed both in rats and mice, thus underlining evolutionary conservation. Furthermore, OTmediated social preference was observed under varying light conditions and environmental settings, that is, in the novel, unknown arena and in the home cage. Although beyond the scope of the current studies, it would be interesting to determine whether blockade of the endogenous OT system would also result in social avoidance in females in our paradigm. This would seem likely in the light of studies showing alterations in social recognition and anxiety in female OT knockout mice (Crawley et al, 2007) and OTR antisense DNA-treated female mice (Choleris et al, 2007).

Intracerebral release of OT in specific brain regions was found to be increased in response to a variety of social stimuli, including mother-offspring interactions, maternal aggression, mating in males and females, and exposure to 

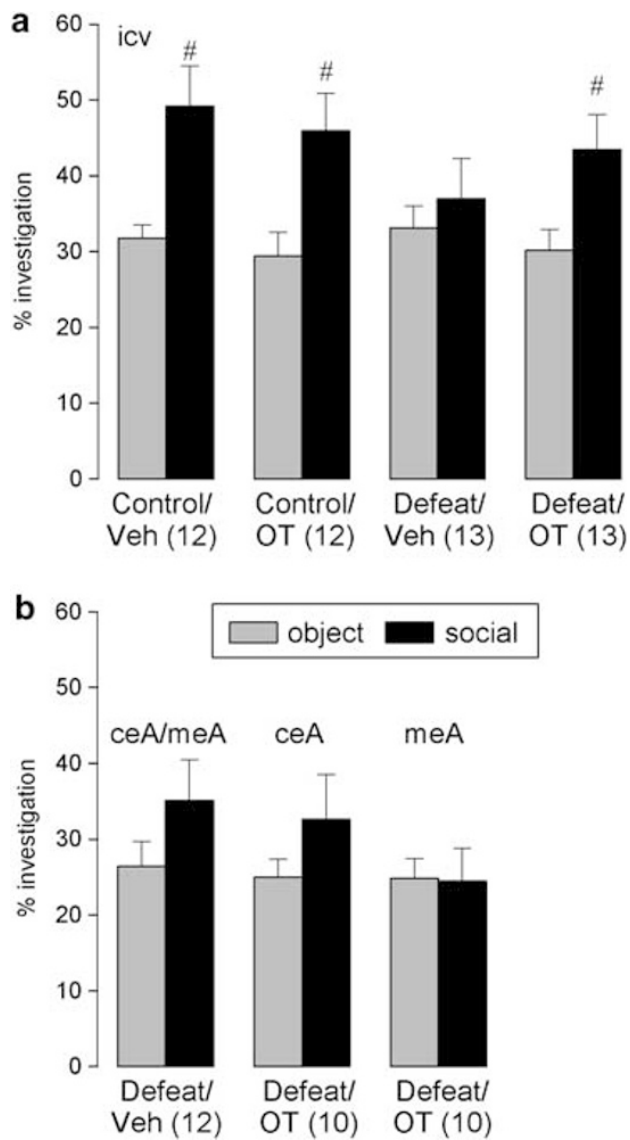

Figure 4 Social preference behavior of socially defeated and control rats after either vehicle (Veh) or oxytocin (OT) were applied i.c.v. $(0 . \mid \mu \mathrm{g} / 5 \mu \mathrm{l}, \mathrm{a})$ or bilaterally into the central (ceA) or medial (meA) amygdala (b) $(0.0|\mu \mathrm{g} /| \mu \mathrm{l}) 20 \mathrm{~min}$ prior to the social preference test. Social preference is reflected by the higher percentage of investigation time directed toward the social (black columns) vs the object (grey columns) stimulus during two sequential exposures. Numbers in parentheses reflect group size. Data are means + SEM, ${ }^{\#} p<0.05$ vs object stimulus; three-way or two-way ANOVA for repeated measures followed by Bonferroni post hoc test.

an adult con-specific during social defeat (reviewed in Neumann, 2009; Veenema and Neumann, 2008). In the context of social stimuli, increased OT release could be identified within the hypothalamic PVN (Neumann et al, 1993; Waldherr and Neumann, 2007), the central amygdala (Bosch et al, 2005), the olfactory bulb (Lévy et al, 1995), the mediolateral septum (Ebner et al, 2000), and the nucleus accumbens (Ross et al, 2009). Together with the present findings, these results support the hypothesis that stimulation of the brain OT system by social cues reinforces appropriate social interactions.

In order to localize the pro-social effects of OT, we chose various subnuclei of the amygdala as the most promising target regions. Within the central amygdala, OT exerts anxiolytic effects and regulates social interactions after stress (Bale et al, 2001; Lee et al, 2007; Neumann, 2002). Moreover, the medial amygdala is prominent for its OTdependent role in social recognition (Choleris et al, 2007; Ferguson et al, 2001) and social odor approach (Arakawa et al, 2010), and OT receptors were described in relatively high density in the central, but also the medial, and basolateral amygdala (Lukas et al, 2010; Tribollet et al,
1988). Additionally, within the central amygdala, increased OT release has been demonstrated during social stimuli, that is, during mother-offspring interactions (Bosch et al, 2005). Similarly, human imaging studies suggest an involvement of amygdala subnuclei in oxytocinergic processing of social interactions and fear response (Gamer et al, 2010; Hurlemann et al, 2010; Kirsch et al, 2005; Labuschagne et al, 2010). However, whether OT exerts direct local effects or rather acts via multiple OT-responsive regions upstream of the amygdala after its intranasal application in humans needs to be shown; a question that could be approached using our rodent model. However, neither an acute effect of the OTR-A on social preference, nor of synthetic OT on social defeat-induced social avoidance could be localized within any amygdala subnuclei examined. Thus, we suggest that social preference might require OT actions at yet to be identified brain regions where OT receptors are present, including olfactory bulb, prefrontal cortex, nucleus accumbens, lateral septum, and PVN (Barberis and Tribollet, 1996; Tribollet et al, 1988; Young et al, 1996). These regions are likely to participate as a complex network to orchestrate social approach behavior. The extent to which diffusion processes after dendritic release, which has recently been discussed, impact on such a network and contribute to the behavioral effects of OT remains to be shown (Landgraf and Neumann, 2004; Ludwig and Leng, 2006).

In accordance with previous studies demonstrating social avoidance after repeated or chronic exposure to social defeat (Berton et al, 2006; Haller and Bakos, 2002; Meerlo et al, 1996; Vidal et al, 2007), we show here that a single social defeat exposure, prior to the social preference test, induces social avoidance in male rats. In our study, the social investigation time of defeated rats was even lower than object investigation time, indicating a high level of social anxiety. However, in our hands, loss of social preference could only be induced when the identical defeater rat was used as the social stimulus during the social preference test. This is in line with a study in golden hamsters that also reports specific social avoidance of the former defeater but not of an unfamiliar con-specific (Lai et al, 2005). Synthetic OT was able to rescue social approach behavior under conditions of social defeatinduced social avoidance or social anxiety and, thus, to restore social preference. Despite the role of OT in recognition of familiar con-specifics (Bielsky and Young, 2004), it is unlikely that these effects are due to OTmediated alterations in social recognition because the dose used in this study was ineffective in social recognition (Benelli et al, 1995) and, if anything, OT would have facilitated the recognition of the defeater rat, which would have promoted avoidance rather than the rescue of social avoidance as was found in this study. We further found that synthetic OT did not further increase social preference under basal circumstances. Similarly, in human studies intranasal OT application reduced hyperresponsivity of the amygdala to facial cues in socially anxious patients, while not affecting the response observed in normal patients (Labuschagne et al, 2010). Additionally, in male goldfish (Carassius auratus) i.c.v. infused isotocin increased social approach behavior only in individuals with low sociability (Thompson and Walton, 2004). In this respect animal 


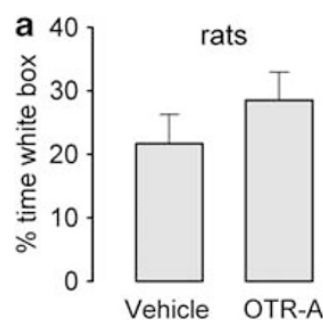

(8)

(8)

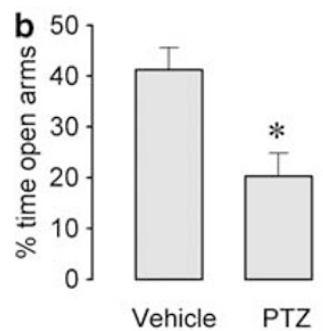

(9)

(9)

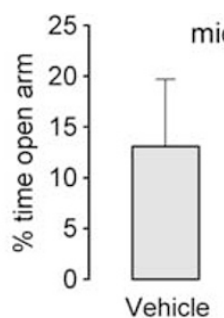

(6)

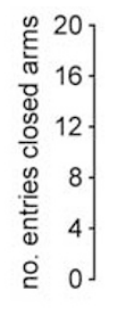

(2)

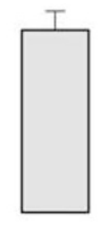

Vehicle

(9) mice

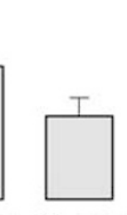

(5)

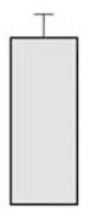

(9)
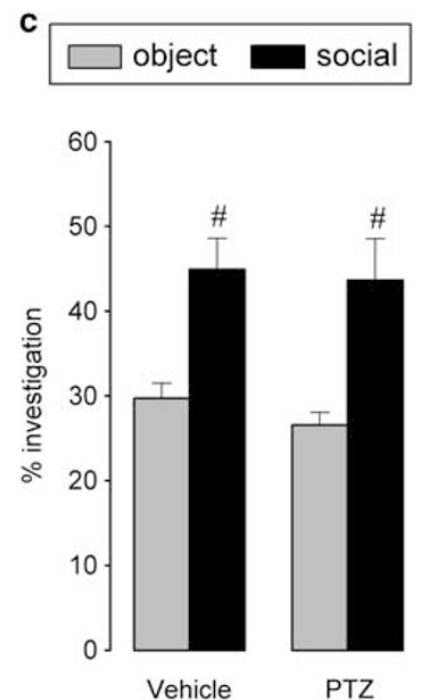

(6)

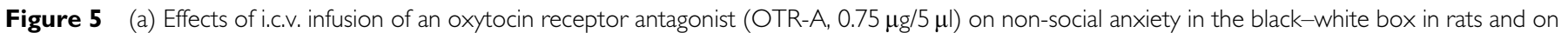

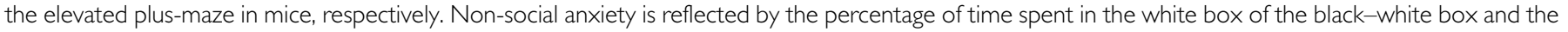

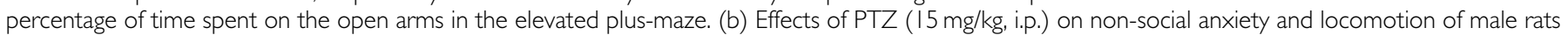

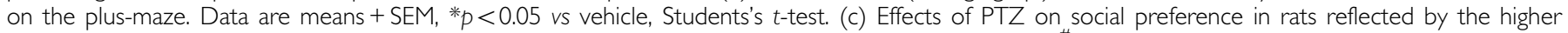

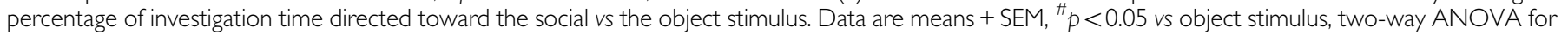
repeated measures followed by Bonferroni post hoc test.

models of low-innate sociability, like the BTBR $\mathrm{T}+\mathrm{tf} / \mathrm{J}$ mice (McFarlane et al, 2008), may be useful in investigating the possible facilitating properties of synthetic OT on social preference.

Remarkably, administration of the vasopressin 1a receptor antagonist was without effect on social preference indicating peptide-specific effects and high specificity of the antagonists used. This is an important finding because vasopressin is a key modulator of various aspects of social behavior in male rodents such as social memory (Engelmann et al, 1994), inter-male aggression (Veenema et al, 2010), and pair bonding (Wang et al, 1998), but exerts rather anxiogenic effects (for review, see Landgraf, 2006).

Owing to the obvious close link between social and nonsocial anxiety, we assessed whether OT actions on social preference were in part because of an OT-mediated reduction in general anxiety. Although profound anxiolytic properties of synthetic OT have been described (Bale et al, 2001; Blume et al, 2008; Slattery and Neumann, 2010; Windle et al, 1997), the role of the endogenous brain OT system in the regulation of anxiety-related behavior needs particular attention. It has been repeatedly shown that anxiolytic effects of endogenous OT can only be identified under conditions of high brain OT activity, such as in lactating dams (Neumann et al, 2000b), and after mating in males (Waldherr and Neumann, 2007). In contrast, blockade of OT receptors in virgin females or males under basal conditions failed to alter the level of anxiety (Neumann et al, 2000a). This is in agreement with the present results in naïve male rats or mice demonstrating that i.c.v.-infused OTR-A did not alter non-social anxiety-related behavior (i) during the social preference test (investigation of the novel object), (ii) in the black-white box (rats), or (iii) on the elevated plus-maze (mice), further substantiating a dissociation between OT effects on social and non-social anxiety. In support, the anxiogenic drug PTZ did, as expected, reduce the time rats spent on the open arms of the elevated plus-maze without eliciting social avoidance. These results show the specificity of the social preference test for social facets of approach behavior, which can be distinguished from parameters mirroring general anxiety. They further demonstrate that the effects of OT on social preference are not due to direct interactions with nonsocial anxiety.

In conclusion, our results provide direct evidence of an important involvement of the brain OT system in the natural occurrence of social preference in male rats and mice. Further, exposure to a single social defeat is efficient to induce social avoidance, which can be reversed by central administration of synthetic OT. However, these pro-social effects of OT are not likely to be mediated by direct actions of OT on the amygdala, but rather require additional regions of a potential social brain network. Furthermore, these effects of OT are specific to social approach behavior as no alteration in non-social anxiety was observed, while - vice versa - increasing non-social anxiety did not alter social preference. Thus, the brain OT system is a promising therapeutic target for the treatment of social phobia or social avoidance as seen in social anxiety disorder and autism spectrum disorders, respectively.

\section{ACKNOWLEDGEMENTS}

We would like to thank Dr Morris Manning for generously providing the neuropeptide receptor antagonists. We also thank Gabriele Schindler and Andrea Havasi for technical assistance and Thomas Stolz and Sahab Arinrad for extensive behavioral observations and experimental support. 


\section{DISCLOSURE}

Funding for this study was provided by the German Research Community (Ne 465/17) and the German Ministry of Education and Science (BMBF 710510). Both resources had no further role in study design; in the collection, analysis and interpretation of data; in the writing of the report; and in the decision to submit the paper for publication. The authors declare no conflict of interest.

\section{REFERENCES}

Andari E, Duhamel JR, Zalla T, Herbrecht E, Leboyer M, Sirigu A (2010). Promoting social behavior with oxytocin in highfunctioning autism spectrum disorders. Proc Natl Acad Sci USA 107: 4389-4394.

Arakawa H, Arakawa K, Deak T (2010). Oxytocin and vasopressin in the medial amygdala differentially modulate approach and avoidance behavior toward illness-related social odor. Neuroscience 171: 1141-1151.

Argiolas A, Melis MR (2004). The role of oxytocin and the paraventricular nucleus in the sexual behaviour of male mammals. Physiology Behavior 83: 309-317.

Bale TL, Davis AM, Auger AP, Dorsa DM, McCarthy MM (2001). CNS region-specific oxytocin receptor expression: importance in regulation of anxiety and sex behavior. J Neurosci 21: 2546-2552.

Barberis C, Tribollet E (1996). Vasopressin and oxytocin receptors in the central nervous system. Crit Rev Neurobiol 10: 119-154.

Baumgartner T, Heinrichs M, Vonlanthen A, Fischbacher U, Fehr E (2008). Oxytocin shapes the neural circuitry of trust and trust adaptation in humans. Neuron 58: 639-650.

Beiderbeck DI, Neumann ID, Veenema AH (2007). Differences in intermale aggression are accompanied by opposite vasopressin release patterns within the septum in rats bred for low and high anxiety. Eur J Neurosci 26: 3597-3605.

Benelli A, Bertolini A, Poggioli R, Menozzi B, Basaglia R, Arletti R (1995). Polymodal dose-response curve for oxytocin in the social recognition test. Neuropeptides 28: 251-255.

Berton O, McClung CA, DiLeone RJ, Krishnan V, Renthal W, Russo $\mathrm{SJ}$ et al (2006). Essential role of BDNF in the mesolimbic dopamine pathway in social defeat stress. Science 311: 864-868.

Bielsky IF, Young LJ (2004). Oxytocin, vasopressin, and social recognition in mammals. Peptides 25: 1565-1574.

Blume A, Bosch OJ, Miklos S, Torner L, Wales L, Waldherr M et al (2008). Oxytocin reduces anxiety via ERK1/2 activation: local effect within the rat hypothalamic paraventricular nucleus. Eur $J$ Neurosci 27: 1947-1956.

Bosch OJ, Meddle SL, Beiderbeck DI, Douglas AJ, Neumann ID (2005). Brain oxytocin correlates with maternal aggression: link to anxiety. J Neurosci 25: 6807-6815.

Caronna EB, Milunsky JM, Tager-Flusberg H (2008). Autism spectrum disorders: clinical and research frontiers. Arch Disease Childhood 93: 518-523.

Cho MM, DeVries AC, Williams JR, Carter CS (1999). The effects of oxytocin and vasopressin on partner preferences in male and female prairie voles (Microtus ochrogaster). Behav Neurosci 113: 1071-1079.

Choleris E, Gustafsson JA, Korach KS, Muglia LJ, Pfaff DW, Ogawa S (2003). An estrogen-dependent four-gene micronet regulating social recognition: a study with oxytocin and estrogen receptor-alpha and -beta knockout mice. Proc Natl Acad Sci USA 100: 6192-6197.

Choleris E, Little SR, Mong JA, Puram SV, Langer R, Pfaff DW (2007). Microparticle-based delivery of oxytocin receptor antisense DNA in the medial amygdala blocks social recognition in female mice. Proc Natl Acad Sci USA 104: 4670-4675.

Crawley JN, Chen T, Puri A, Washburn R, Sullivan TL, Hill JM et al (2007). Social approach behaviors in oxytocin knockout mice: comparison of two independent lines tested in different laboratory environments. Neuropeptides 41: 145-163.

Domes G, Heinrichs M, Michel A, Berger C, Herpertz SC (2007). Oxytocin improves 'mind-reading' in humans. Biol Psychiatry 61: 731-733.

Ebner K, Wotjak CT, Landgraf R, Engelmann M (2000). A single social defeat experience selectively stimulates the release of oxytocin, but not vasopressin, within the septal brain area of male rats. Brain Res 872: 87-92.

Engelmann M, Ebner K, Wotjak CT, Landgraf R (1998). Endogenous oxytocin is involved in short-term olfactory memory in female rats. Behav Brain Res 90: 89-94.

Engelmann M, Ludwig M, Landgraf R (1994). Simultaneous monitoring of intracerebral release and behavior: endogenous vasopressin improves social recognition. J Neuroendocrinol 6: 391-395.

Ferguson JN, Aldag JM, Insel TR, Young LJ (2001). Oxytocin in the medial amygdala is essential for social recognition in the mouse. J Neurosci 21: 8278-8285.

Ferguson JN, Young LJ, Hearn EF, Matzuk MM, Insel TR, Winslow JT (2000). Social amnesia in mice lacking the oxytocin gene. Nat Genet 25: 284-288.

Gamer M, Zurowski B, Büchel C (2010). Different amygdala subregions mediate valence-related and attentional effects of oxytocin in humans. Proc Natl Acad Sci USA 107: 9400-9405.

Goodson JL, Schrock SE, Klatt JD, Kabelik D, Kingsbury MA (2009). Mesotocin and nonapeptide receptors promote estrildid flocking behavior. Science 325: 862-866.

Guastella AJ, Einfeld SL, Gray KM, Rinehart NJ, Tonge BJ, Lambert TJ et al (2010). Intranasal oxytocin improves emotion recognition for youth with autism spectrum disorders. Biol Psychiatry 67: 692-694.

Guastella AJ, Howard AL, Dadds MR, Mitchell P, Carson DS (2009). A randomized controlled trial of intranasal oxytocin as an adjunct to exposure therapy for social anxiety disorder. Psychoneuroendocrinology 34: 917-923.

Guastella AJ, Mitchell PB, Dadds MR (2008). Oxytocin increases gaze to the eye region of human faces. Biol Psychiatry 63: 3-5.

Haller J, Bakos N (2002). Stress-induced social avoidance: a new model of stress-induced anxiety? Physiol Behav 77: 327-332.

Hollander E, Bartz J, Chaplin W, Phillips A, Sumner J, Soorya L et al (2007). Oxytocin increases retention of social cognition in autism. Biol Psychiatry 61: 498-503.

Hurlemann R, Patin A, Onur OA, Cohen MX, Baumgartner T, Metzler S et al (2010). Oxytocin enhances amygdala-dependent, socially reinforced learning and emotional empathy in humans. J Neurosci 30: 4999-5007.

Kendrick KM (2000). Oxytocin, motherhood and bonding. Exp Physiol 85: 111S-124S.

Kirsch P, Esslinger C, Chen Q, Mier D, Lis S, Siddhanti S et al (2005). Oxytocin modulates neural circuitry for social cognition and fear in humans. J Neurosci 25: 11489-11493.

Kosfeld M, Heinrichs M, Zak PJ, Fischbacher U, Fehr E (2005). Oxytocin increases trust in humans. Nature 435: 673-676.

Labuschagne I, Phan KL, Wood A, Angstadt M, Chua P, Heinrichs $\mathrm{M}$ et al (2010). Oxytocin attenuates amygdala reactivity to fear in generalized social anxiety disorder. Neuropsychopharmacology 35: 2403-2413.

Lai W-S, Ramiro L-LR, Yu HA, Johnston RE (2005). Recognition of familiar individuals in golden hamsters: a new method and functional neuroanatomy. J Neurosci 25: 11239-11247.

Landgraf $\mathrm{R}$ (2006). The involvement of the vasopressin system in stress-related disorders. CNS Neurol Disord Drug Targets 5: 167-179.

Landgraf R, Neumann ID (2004). Vasopressin and oxytocin release within the brain: a dynamic concept of multiple and variable modes of neuropeptide communication. Front Neuroendocrinol 25: $150-176$. 
Lee PR, Brady DL, Shapiro RA, Dorsa DM, Koenig JI (2007). Prenatal stress generates deficits in rat social behavior: Reversal by oxytocin. Brain Res 1156: 152-167.

Lévy F, Kendrick KM, Goode JA, Guevara-Guzman R, Keverne EB (1995). Oxytocin and vasopressin release in the olfactory bulb of parturient ewes: changes with maternal experience and effects on acetylcholine, [gamma]-aminobutyric acid, glutamate and noradrenaline release. Brain Res 669: 197-206.

Ludwig M, Leng G (2006). Dendritic peptide release and peptidedependent behaviours. Nat Rev Neurosci 7: 126-136.

Lukas M, Bredewold R, Neumann ID, Veenema AH (2010). Maternal separation interferes with developmental changes in brain vasopressin and oxytocin receptor binding in male rats. Neuropharmacology 58: 78-87.

McCarthy MM (1990). Oxytocin inhibits infanticide in female house mice (Mus domesticus). Horm Behav 24: 365-375.

McFarlane HG, Kusek GK, Yang M, Phoenix JL, Bolivar VJ, Crawley JN (2008). Autism-like behavioral phenotypes in BTBR $\mathrm{T}+\mathrm{tf} / \mathrm{J}$ mice. Genes Brain Behavior 7: 152-163.

Meerlo P, Overkamp GJ, Daan S, Van Den Hoofdakker RH, Koolhaas JM (1996). Changes in behaviour and body weight following a single or double social defeat in rats. Stress 1: 21-32.

Merikangas KR, Angst J (1995). Comorbidity and social phobia: evidence from clinical, epidemiologic, and genetic studies. Eur Arch Psychiatry Clin Neurosci 244: 297-303.

Neumann I, Russell JA, Landgraf R (1993). Oxytocin and vasopressin release within the supraoptic and paraventricular nuclei of pregnant, parturient and lactating rats: a microdialysis study. Neuroscience 53: 65-75.

Neumann ID (2002). Involvement of the brain oxytocin system in stress coping: interactions with the hypothalamo-pituitaryadrenal axis. Prog Brain Res 139: 147-162.

Neumann ID (2009). The advantage of social living: brain neuropeptides mediate the beneficial consequences of sex and motherhood. Front Neuroendocrinol 30: 483-496.

Neumann ID, Torner L, Wigger A (2000b). Brain oxytocin: differential inhibition of neuroendocrine stress responses and anxiety-related behaviour in virgin, pregnant and lactating rats. Neuroscience 95: 567-575.

Neumann ID, Veenema AH, Beiderbeck DI (2010). Aggression and anxiety: social context and neurobiological links. Frontiers Behav Neurosci 5: 12.

Neumann ID, Wigger A, Torner L, Holsboer F, Landgraf R (2000a). Brain oxytocin inhibits basal and stress-induced activity of the hypothalamo-pituitary-adrenal axis in male and female rats: partial action within the paraventricular nucleus. J Neuroendocrinol 12: 235-243.

Pedersen CA, Ascher JA, Monroe YL, Prange Jr AJ (1982). Oxytocin induces maternal behavior in virgin female rats. Science 216: 648-650.

Pellow S, Chopin P, File SE, Briley M (1985). Validation of open: closed arm entries in an elevated plus-maze as a measure of anxiety in the rat. J Neurosci Methods 14: 149-167.

Popik P, van Ree JM (1991). Oxytocin but not vasopressin facilitates social recognition following injection into the medial preoptic area of the rat brain. Eur Neuropsychopharmacol 1: $555-560$.

Ring RH, Malberg JE, Potestio L, Ping J, Boikess S, Luo B et al (2006). Anxiolytic-like activity of oxytocin in male mice: behavioral and autonomic evidence, therapeutic implications. Psychopharmacology (Berl) 185: 218-225.

Ross HE, Cole CD, Smith Y, Neumann ID, Landgraf R, Murphy AZ et al (2009). Characterization of the oxytocin system regulating affiliative behavior in female prairie voles. Neuroscience 162: 892-903.
Savaskan E, Ehrhardt R, Schulz A, Walter M, Schächinger H (2008). Post-learning intranasal oxytocin modulates human memory for facial identity. Psychoneuroendocrinology 33: 368-374.

Schulze HG, Gorzalka BB (1991). Oxytocin effects on lordosis frequency and lordosis duration following infusion into the medial pre-optic area and ventromedial hypothalamus of female rats. Neuropeptides 18: 99-106.

Slattery DA, Neumann ID (2010). Chronic icv oxytocin attenuates the pathological high anxiety state of selectively bred Wistar rats. Neuropharmacology 58: 56-61.

Takayanagi Y, Yoshida M, Bielsky IF, Ross HE, Kawamata M, Onaka $\mathrm{T}$ et al (2005). Pervasive social deficits, but normal parturition, in oxytocin receptor-deficient mice. Proc Natl Acad Sci USA 102: 16096-16101.

Thompson MR, Callaghan PD, Hunt GE, Cornish JL, McGregor IS (2007). A role for oxytocin and 5-HT1A receptors in the prosocial effects of 3,4 methylenedioxymethamphetamine ('ecstasy'). Neuroscience 146: 509-514.

Thompson RR, Walton JC (2004). Peptide effects on social behavior: effects of vasotocin and isotocin on social approach behavior in male goldfish (Carassius auratus). Behav Neurosci 118: $620-626$.

Tribollet E, Barberis C, Jard S, Dubois-Dauphin M, Dreifuss JJ (1988). Localization and pharmacological characterization of high affinity binding sites for vasopressin and oxytocin in the rat brain by light microscopic autoradiography. Brain Res 442: 105-118.

van Leengoed E, Kerker E, Swanson HH (1987). Inhibition of postpartum maternal behaviour in the rat by injecting an oxytocin antagonist into the cerebral ventricles. J Endocrinol 112: 275-282.

Veenema AH, Beiderbeck DI, Lukas M, Neumann ID (2010). Distinct correlations of vasopressin release within the lateral septum and the bed nucleus of the stria terminalis with the display of intermale aggression. Hormones Behav 58: 273-281.

Veenema AH, Neumann ID (2008). Central vasopressin and oxytocin release: regulation of complex social behaviours. Prog Brain Res 170: 261-276.

Vidal J, Bie J, Granneman RA, Wallinga AE, Koolhaas JM, Buwalda B (2007). Social stress during adolescence in Wistar rats induces social anxiety in adulthood without affecting brain monoaminergic content and activity. Physiol Behav 92: 824-830.

Waldherr M, Neumann ID (2007). Centrally released oxytocin mediates mating-induced anxiolysis in male rats. Proc Natl Acad Sci USA 104: 16681-16684.

Wang Z, Young LJ, De Vries GJ, Insel TR (1998). Voles and vasopressin: a review of molecular, cellular, and behavioral studies of pair bonding and paternal behaviors. Prog Brain Res 119: 483-499.

Williams JR, Insel TR, Harbaugh CR, Carter CS (1994). Oxytocin administered centrally facilitates formation of a partner preference in female prairie voles (Microtus ochrogaster). J Neuroendocrinol 6: 247-250.

Windle RJ, Shanks N, Lightman SL, Ingram CD (1997). Central oxytocin administration reduces stress-induced corticosterone release and anxiety behavior in rats. Endocrinology 138: 2829-2834.

Witt DM, Insel TR (1991). A selective oxytocin antagonist attenuates progesterone facilitation of female sexual behavior. Endocrinology 128: 3269-3276.

Witt DM, Winslow JT, Insel TR (1992). Enhanced social interactions in rats following chronic, centrally infused oxytocin. Pharmacol Biochem Behav 43: 855-861.

Young LJ, Huot B, Nilsen R, Wang Z, Insel TR (1996). Species differences in central oxytocin receptor gene expression: comparative analysis of promoter sequences. J Neuroendocrinol 8: $777-783$

Supplementary Information accompanies the paper on the Neuropsychopharmacology website (http://www.nature.com/npp) 